\title{
Progress in Interventional Pulmonology
}

\author{
Pallav L. Shah ${ }^{\mathrm{a}-\mathrm{c}}$ Felix J.F. Herth ${ }^{\mathrm{d}}$ \\ ${ }^{a}$ Royal Brompton and Harefield NHS Foundation Trust, London, UK; ${ }^{b}$ Chelsea and Westminster Hospital NHS \\ Foundation Trust, London, UK; ${ }^{C}$ National Heart and Lung Institute, Imperial College London, London, UK; \\ ${ }^{\mathrm{d}}$ Department of Pneumology and Critical Care Medicine, Thoraxklinik, Translational Lung Research Center \\ Heidelberg, University of Heidelberg, Heidelberg, Germany
}

Interventional pulmonology has progressed at an incredible rate over the last decade. We have seen the evolution of bronchoscopy from a simple optical instrument to evaluate the central airways and obtain some samples through to advanced bronchoscopy with the development of endobronchial ultrasound which permits the sampling of mediastinal lymph nodes through to masses adjacent to the central tracheobronchial tree. This has completely revolutionized the diagnosis and staging of lung cancer. Its uptake globally has been breathtaking. Following closely has been the development of therapeutic bronchoscopy. Rigid bronchoscopy with tumour debulking with or without stent insertion was mainstream in the last millennium, but this side of the millennium we have seen the development of novel treatments for asthma, emphysema, and chronic obstructive pulmonary disease delivered through the flexible bronchoscope [1].

Guidelines such as the advanced bronchoscopy guidelines from the British Thoracic Society [2,3] are focused on evidence of the safety and effectiveness of these interventions but do not provide sufficient guidance on key aspects of the procedure such as patient selection, patient management prior to and following the procedure, and the fine details of the procedure itself. Furthermore, due to restrictions on length even scientific papers provide just the bare details of the procedure. Following the success of the best practice paper on endobronchial valves [4], Respiration has developed a thematic series focused on the best practice of interventional pulmonology procedures that are becoming more established, at least in Europe. The series is intended to evaluate technologies that have a good evidence base for their safety and efficacy with at least some randomized controlled data.

The first paper of this series [5] presents the best practice recommendations for bronchial thermoplasty for severe asthma. It recommends a multidisciplinary team approach in asthma centres in order to select optimal patients for treatment. This would also ensure higher case volumes and hence improve the centres' treatment experience. This is particularly important as the evidence base is formed on treating patients with mild-to-severe asthma. However, our current practice appears to focus on treating patients with very severe disease, often those for whom other therapies have failed. The procedure itself is performed on 3 separate occasions with a gap of at least 3 weeks, with the right lower lobe treated first, followed by the left lower lobe and finally the upper lobes. A systematic approach should be taken to ensure complete treat-

\section{KARGER}

(C) 2018 S. Karger AG, Basel

E-Mail karger@karger.com

www.karger.com/res
Prof. Pallav L. Shah

Royal Brompton Hospital

Sydney Street

London SW3 6NP (UK)

E-Mail pallav.shah@imperial.ac.uk 
ment. With respect to patient management during their procedure, the authors outline strategies for ensuring that an optimal number of activations are delivered. Hence, consideration of sedation and anaesthesia is also important for this procedure.

The next paper in our thematic series focuses on cryotransbronchial lung biopsy [6]. Interest in this area has grown dramatically, and although this procedure is simple to perform, complications can be significant and fatal. Once again a multidisciplinary approach is recommended for patient selection. Massive airway haemorrhage and pneumothorax are the two major complications, and bronchoscopists should be proficient at managing these complications prior to embarking on performing these procedures. An expert statement on this technique already exists [7], but the current publication is providing detailed practical recommendations. The authors strongly recommend that measures to control bleeding, such as tamponade balloons, should prophylactically be utilized instead of attempting to place these blockers in the event of severe haemorrhage. The procedure itself is best performed on an intubated patient under general anaesthesia and with fluoroscopic guidance to ensure that the cryobiopsy is performed from the optimal location. A more central biopsy entails a greater risk of bleeding, whereas there is a greater risk of pneumothorax if the pleural surface is apposed.

The two subsequent articles in this series $[8,9]$ focus on lung volume reduction techniques for the treatment of patients with severe emphysema: endobronchial coils and vapour. In keeping with the best practice theme, a multidisciplinary approach is again emphasized. Patient selection and the role of quantitative analysis of computed tomograms of the thorax are discussed. The degree of destruction and the morphological pattern of the emphysema are key factors for the choice of treatment. With endobronchial coils the procedure is performed in 2 stages, with one lobe treated first and the contralateral lung treated 4-8 weeks later. Vapour treatment can also be staged in 2-3 procedures depending on a patient's response. The major differences between the approaches are that one targets the whole lobe and leaves nitinol implants in situ within the lung, whereas the vapour approach targets segments within the lobe with no implant left within the lung. Both procedures are considered irreversible, although it is possible to remove a few endobronchial coils. The major issue with vapour is the development of an inflammatory response, and treatment of the correct segment with the correct dose is essential to minimize the risk of acute respiratory distress syndrome. Endobronchial coils also induce a localized inflammatory response termed "coil-associated opacity," which is often regarded as a sign of response.

As mentioned earlier in this Editorial, best practice recommendations for endobronchial valves have already been published [4], and these two additional articles complete the series. Further therapeutic developments targeted nerve denervation for COPD and cryospray ablative therapies for chronic bronchitis - are already on the horizon, which may progress sufficiently to reach clinical practice. Furthermore, therapeutic bronchoscopy may refocus on cancer with the development of flexible ablative devices such as flexible radiofrequency and microwave catheters for treating peripheral lung tumours in conjunction with improved navigation techniques.

\section{References}

1 Shah PL, Herth FJ, van Geffen WH, Deslee G, Slebos DJ: Lung volume reduction for emphysema. Lancet Respir Med 2017;5:147-156.

2 Du Rand IA, Barber PV, Goldring J, et al: Summary of the British Thoracic Society guidelines for advanced diagnostic and therapeutic flexible bronchoscopy in adults. Thorax 2011;66:1014-1015.

3 Du Rand IA, Barber PV, Goldring J, et al: British Thoracic Society guideline for advanced diagnostic and therapeutic flexible bronchoscopy in adults. Thorax 2011;66(suppl 3):iii1iii21.

4 Slebos DJ, Shah PL, Herth FJ, Valipour A: Endobronchial valves for endoscopic lung volume reduction: best practice recommendations from expert panel on endoscopic lung volume reduction. Respiration 2017;93:138150.

5 Bonta PI, Chanez P, Annema JT, Shah PL, Niven R: Bronchial thermoplasty in severe asthma: best practice recommendations from an expert panel. Respiration DOI: $10.1159 / 000488291$.

6 Colella S, Haentschel M, Shah PL, Poletti V, Hetzel J: Transbronchial lung cryobiopsy in interstitial lung diseases: best practice paper. Respiration DOI: 10.1159/000488910.

7 Hetzel J, Maldonado F, Ravaglia C, Wells AU, Colby TV, Tomassetti S, Ryu JH, Fruchter O, Piciucchi S, Dubini A, Cavazza A, Chilosi M, Sverzellati N, Valeyre D, Leduc D, Walsh SLF, Gasparini S, Hetzel M, Hagmeyer L, Haentschel M, Eberhardt R, Darwiche K, Yar- mus LB, Torrego A, Krishna G, Shah PL, Annema JT, Herth FJF, Poletti V: Transbronchial cryobiopsies for the diagnosis of diffuse parenchymal lung diseases: expert statement from the Cryobiopsy Working Group on Safety and Utility and a call for standardization of the procedure. Respiration 2018;95:188-200.

8 Gompelmann D, Shah PL, Valipour A, Herth FJF: Bronchoscopic thermal vapor ablation: best practice recommendations from Expert Panel on Endoscopic Lung Volume Reduction. Respiration 2018, in press.

9 Slebos D-J, Ten Hacken N, Hetzel M, Herth FJF, Shah PL: Endobronchial coils for endoscopic lung volume reduction: best practice recommendations from an expert panel. Respiration 2018, in press. 